\title{
Enantioselective photodeconjugation of conjugated esters and lactones
}

\author{
Jean-Pierre Pete*, Françoise Hénin, Reza Mortezaei, Jacques Muzart and Olivier Piva \\ Laboratoire de Photochimie, Unité Associée au CNRS $n^{\circ} 459$, Université de \\ Reims Champagne-Ardenne, 51062 Reims Cédex, France
}

\begin{abstract}
The photodeconjugation of conjugated esters and lactones in the presence of small amounts of chiral catalysts is enantioselective. The enantiomeric excess is very sensitive to the conditions of the reaction. When chiral amino alcohols are used as chiral catalysts a synergism is observed between the effect of the amino and hydroxyl groups on the optical purity of the deconjugated molecules. The chiral discrimination between the two diastereoisomeric transitions states leading to the $R$ and $S$ configuration of the product is

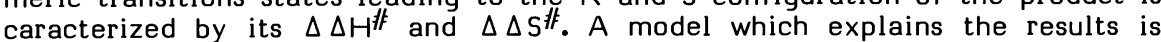
proposed and some examples of generalisation of these studies are described.
\end{abstract}

Optically active molecules are very important in nature and the preparation of pure enantiomers either by resolution of racemates or more recently by asymmetric synthesis has become a challenge of high practical importance for the organic chemist. New very efficient methodologies such as the Sharpless oxidation allowing the synthesis of almost pure enantiomers have been proposed by organic chemists. However, up to now, photochemistry has not been very successful in the field of enantioselective reactions (1).

To induce asymmetry, several photochemical ways have been explored:

Circularly polarized light (C.P.L.) as the source of chirality, of great theoretical importance, has been used for the enantioselective synthesis of hexahelicenes. However, the optical purity of the products is very low. When C.P.L. is used for the enantioselective destruction of a racemate, high optical purities can be obtained for high conversion rates (2). Unfortunately, high optical purities require the destruction of most of the starting racemate.

The bimolecular photoreaction of a chiral molecule with a non chiral molecule may lead to considerable asymmetric induction. Furthermore, the diastereoisomers can be isolated in pure forms and, after removal of the chiral inductor, high optical yields can be obtained. Among these reactions, photocycloadditions of conjugated chiral molecules to alkenes seems very promising for synthetic purposes (3). In some cases the chiral inductor is consumed during the photochemical step and therefore cannot be easily regenerated. Photochemical reductions of ketones by enantiomerically pure amines have also been studied but the optical purity of the alcohols formed remains low (4).

The use of chiral sensitizers (5) or chiral solvents (6) also gave very disappointing results in inducing enantioselectivities.

The definition of highly enantioselective or very diastereoselective photoreaction would have important consequences in organic synthesis and we examined different possibilities for increasing the enantioselectivity of photochemical reactions. A first possibility would be to create strong interactions between the chiral inductor and the excited state in the transition state leading to the products. Unfortunately, in most cases the lifetimes of the excited states are not long enough to allow strong bimolecular interactions with a chiral catalyst before the deactivation of the excited state.

Some photochemical reactions produce ground state intermediates too unstable to be isolated but having lifetimes far longer than the starting excited states enabling their chemical trapping. In principle, it would be possible to induce the enantioselective transformation of such ground state intermediates if they could develop strong interactions with a chiral agent. To test this idea we turned on the photodeconjugation of aliphatic $\alpha, \beta$-unsaturated carbonyl compounds (7) and especially conjugated esters (8) or lactones (9). The photodeconjugation reaction of $\alpha, \beta$-unsaturated esters can be very selective and almost quantitative. At $254 \mathrm{~nm}$, the starting ester absorbs UV light far more strongly than the deconjugated product. In polar media, the reaction can be stopped when all the starting material has disappeared. After elimination of the solvent, the deconjugated ester is usually the only new product. 
From careful mechanistic studies, the photodeconjugation is known to involve an intramolecular $\gamma$-hydrogen abstraction of the allylic hydrogen from the singlet excited state (10).

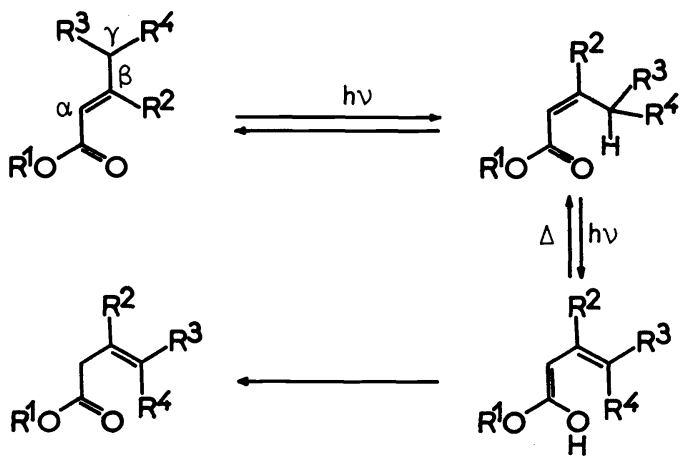

It has been proposed that the photoenolic intermediate might be formed in a concerted antarafacial [1,5] sigmatropic shift (10). The photodienol does not accumulate in the solution and is transformed back to the starting molecule by a thermal suprafacial [1,5] sigmatropic shift or is deconjugated. The tautomerism between the dienol and the deconjugated carbonyl compound is subject to base and even acid catalysis $(10,11)$.

When a conjugated ester 1 is $\alpha$-substituted, there is creation of a new asymmetric center during the reaction and the deconjugated ester $\underline{2}$ should be formed enantioselectively in the presence of a chiral catalyst (I*).

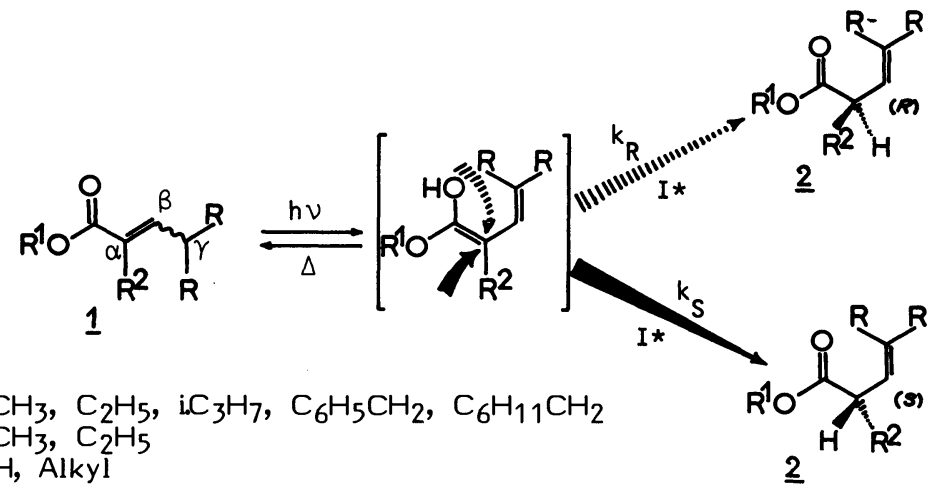

The strong acidity of the $\mathrm{OH}$ group in the dienol (12) allows strong hydrogen bonding with amines in non polar solvents (13). The use of a chiral amine as catalyst should be possible not only to interact very strongly with the intermediate but also to catalyse the protonation $\alpha$ to the carbonyl function.

We can also assume that there is a stationary state where the dienol is kept at low and constant concentration. As the chiral basic catalyst should not be consumed during the irradiation, a low concentration of $I^{*}$ would be needed (14).

The irradiation of $\underline{1 d}$ in presence of (-) ephedrine $2 \mathrm{a}$ as an example will illustrate that our previous assumptions are well founded and the results are summarized in table 1 and figure 1.

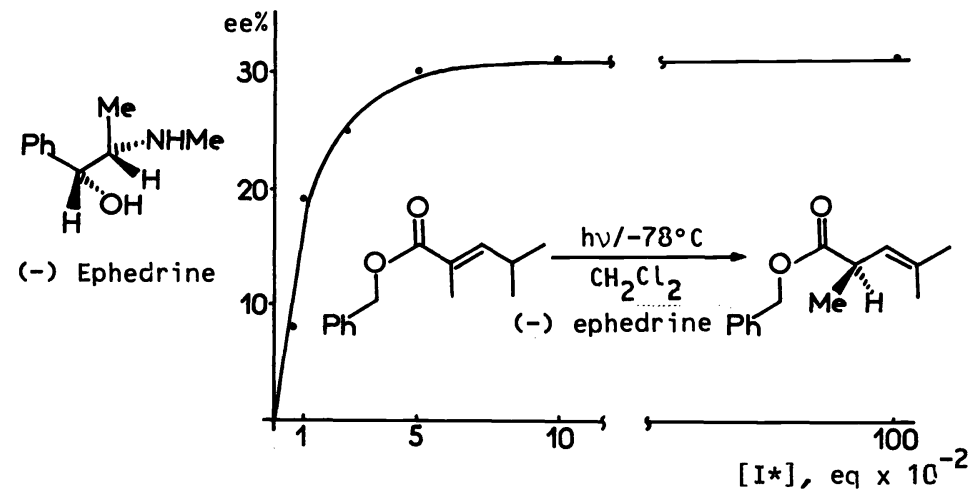

Figure 1 : Effect of the relative concentrations of $1 \mathrm{~d}$ and (-) ephedrine on the enantioselectivity of the photodeconjugation of $\overline{1 \mathrm{~d}}$ in $\mathrm{CH}_{2} \mathrm{Cl}_{2}$ at $-78^{\circ} \mathrm{C}$ 
Table 1 : Solvent and temperature effect on the photodeconjugation of benzyl 2,4-dimethyl2-pentenoate 1d (a)

\begin{tabular}{|c|c|c|c|c|c|}
\hline Inductor & Solvent & $\mathrm{T}^{\circ} \mathrm{C}$ & Isolated yield $\%$ & $\begin{array}{l}e e \% \\
\text { (b) }\end{array}$ & $\begin{array}{l}\text { Configuration } \\
\text { of the major } \\
\text { enantiomer }\end{array}$ \\
\hline \multirow[t]{6}{*}{ (+) ephedrine } & $\mathrm{CH}_{2} \mathrm{Cl}_{2}$ & -40 & 64 & 37 & $\mathrm{~S}$ \\
\hline & $\mathrm{n}$ hexane & -40 & 70 & 28 & S \\
\hline & $\mathrm{C}_{2} \mathrm{H}_{5} \mathrm{OC}_{2} \mathrm{H}_{5}$ & -40 & 70 & 6 & $\mathrm{~s}$ \\
\hline & $\mathrm{CH}_{3} \mathrm{CN}$ & -40 & 65 & 0 & - \\
\hline & $\mathrm{CH}_{2} \mathrm{Cl}_{2}$ & -78 & 78 & 31 & $\mathrm{~S}$ \\
\hline & hexane & -78 & 66 & 41 & S \\
\hline (-) ephedrine & $\begin{array}{l}\mathrm{CH}_{2} \mathrm{Cl}_{2} \\
\mathrm{CH}_{2} \mathrm{Cl}_{2}^{2}\end{array}$ & $\begin{array}{l}25 \\
-\quad 78\end{array}$ & $\begin{array}{l}71 \\
71\end{array}$ & $\begin{array}{c}22.5 \\
28\end{array}$ & $\begin{array}{l}\mathrm{R} \\
\mathrm{R}\end{array}$ \\
\hline
\end{tabular}

a) The irradiations were carried out at $254 \mathrm{~nm}$. The initial concentration of $1 \mathrm{~d}$ was $10^{-2}{\mathrm{M} . \mathrm{L}^{-1}}^{-1}$ and the concentration of the inductor $10^{-3} \mathrm{M} \cdot \mathrm{L}^{-1}$.

b) ee $\%=100 \times \frac{R-S}{R+S}$.

At $-40^{\circ} \mathrm{C}$, we observe a very important enantioselectivity for the deconjugation of $1 \mathrm{~d}$ in the presence of ephedrine. It was anticipated that the best interactions between the dienol and the inductor would be obtained when the competitive interactions with the solvent would be minimized. Table 1 shows that is indeed the case since no asymmetric induction was observed in hydroxylic solvents or in solvents having basic properties (ether, acetonitrile). Furthermore, the presence of traces of moisture prevents completely the asymmetric induction.

The lowering of the temperature from room temperature to $-40^{\circ} \mathrm{C}$ in methylene chloride or n-hexane strengthens the bimolecular interactions of enol-ephedrine and therefore increases the enantioselectivity. At low temperatures, the solubility of ephedrine is limited in non polar solvents. However, the minute and constant concentration in dienol allows maximum effects when the concentration of the chiral catalyst represents at least 0.05 equivalent of the concentration of the starting ester.

To try to understand the type of interactions developed between the dienol and the inductor, we studied the influence of the nature of chiral agent and the effect of the substitution of the starting ester on the enantioselectivity (Tables 2 and 3) $(15,16)$.

At a constant temperature $\left(-78^{\circ} \mathrm{C}\right)$, it is very striking to note that the enantioselectivity is kept very low when chiral amines having no other polar functions or when chiral alcohols bearing no amino group are used as chiral inductors. In contrast, chiral $\alpha$-aminoalcohols all induce significant asymmetric induction. There seems to exist a synergism between the effect of the amino and hydroxy groups of the chiral aminoalcohols on the enantiomeric excess of the photodeconjugation of 1.

Furthermore, for all the $\alpha$-aminoalcohols used as inductors the configuration of the newly created asymmetric center seems to be correlated with the configuration of the asymmetric carbon linked to the amino group in the inductor. Inversion of the configuration of this asymmetric center of the inductor reverses the configuration at $\mathrm{C}-2$ in the deconjugated ester although the configuration of the carbon atom bearing the hydroxyl group has no effect on the configuration of the major enantiomer of $\underline{2}$.<smiles>[R3]CC1=C([R])CCO1</smiles>

3. hv<smiles>[R3]C=C([R])C1CCOC1=O</smiles>

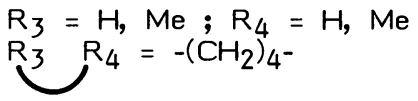

The enantioselective photodeconjugation can be generalized to other esters 1 and to $\alpha$-alkylidene lactones (17) (Table 3). However, when the $\beta$-carbon atom is disubstituted as in $3 \mathrm{~b}-3 \mathrm{c}$ we observe no enantiomeric excess in the $\beta, \gamma$-unsaturated lactone which is isolated in high yields. This effect of a $\beta$-substituent is far more important than the modification of the size of of the $\alpha$ - or $\gamma$-substituents. This might indicate that the chiral discrimination in the diastereoselective transition states involves a steric interaction between the vinyl group of the dienol and the environment of the asymmetric carbon bearing the amine function of the amino alcohol. 
Table 2 : Influence of the nature of the chiral catalyst on the photodeconjugation of $1 \mathrm{~d}(\mathrm{a})$

\begin{tabular}{|c|c|c|c|c|c|c|}
\hline \multirow[b]{2}{*}{ Inductor } & \multicolumn{2}{|c|}{ Configuration } & \multirow[b]{2}{*}{$\begin{array}{c}\text { Conv. } \\
\%\end{array}$} & \multirow[b]{2}{*}{$\begin{array}{c}\text { Yield } \\
\%\end{array}$} & \multirow[b]{2}{*}{$\begin{array}{l}\text { Major. } \\
\text { conf. }\end{array}$} & \multirow[b]{2}{*}{ ee $\%$} \\
\hline & & & & & & \\
\hline $\begin{array}{c}(-) \text { ephedrine } \\
(+) \text { ephedrine } \\
(+) \text { menthol } \\
(-) \text { octanol } \\
(-) \alpha \text {-phenylethylamine } \\
(+) \text { O-methylephedrine } \\
\text { cinchonidine } \\
(-) \text { N-methylephedrine } \\
(-) \text { nor-ephedrine } \\
(+) \psi \text {-ephedrine } \\
\text { (+) N-methylvalinol } \\
\text { L-isoleucinol }\end{array}$ & $\begin{array}{l}R \\
S \\
R \\
R \\
- \\
S \\
R \\
R \\
R \\
S \\
- \\
-\end{array}$ & $\begin{array}{l}\text { S } \\
R \\
- \\
- \\
\text { S } \\
R \\
S \\
S \\
S \\
S \\
S \\
S\end{array}$ & $\begin{array}{l}99 \\
97 \\
86 \\
90 \\
92 \\
91 \\
\text { (b) } \\
100 \\
95 \\
97 \\
98 \\
96\end{array}$ & $\begin{array}{l}71 \\
78 \\
81 \\
57 \\
60 \\
70 \\
73 \\
80 \\
72 \\
70 \\
71 \\
75\end{array}$ & $\begin{array}{l}R \\
S \\
- \\
- \\
R \\
S \\
R \\
R \\
R \\
R \\
R \\
R\end{array}$ & $\begin{array}{c}28 \\
31 \\
- \\
- \\
4 \\
7 \\
37 \\
6 \\
14 \\
4 \\
14 \\
14\end{array}$ \\
\hline
\end{tabular}

(a) The irradiations were carried out at $254 \mathrm{~nm}$ and $-78^{\circ} \mathrm{C} \cdot$ in $\mathrm{CH}_{2} \mathrm{Cl}$. . The initial concentration of the conjugated ester was $10^{-2} \mathrm{M} \cdot \mathrm{L}^{-1}$ and the concentration of the inductor was $10^{-3} \mathrm{M} \cdot \mathrm{L}^{-1}$.

(b) Not determined.

Table 3 : Influence of the nature of the ester or lactone on the enantioselectivity of the photodeconjugation of $\underline{1}\left(\mathrm{R}=\mathrm{CH}_{3}\right)$ or $\underline{3}$ (a)

\begin{tabular}{|c|c|c|c|c|c|c|}
\hline $\begin{array}{l}\text { Starting } \\
\text { material }\end{array}$ & $R_{1}$ or $R_{3}$ & $R_{2}$ or $R_{4}$ & Inductor & $\begin{array}{l}\text { Yield } \\
\%\end{array}$ & $\begin{array}{c}\underline{2} \text { or } \underline{4} \\
\text { Configuration } \\
\text { at } \mathrm{C}-2\end{array}$ & $\begin{array}{l}\text { ee } \% \\
\text { (b) }\end{array}$ \\
\hline$\underline{1 \mathrm{a}}$ & $\mathrm{CH}_{3}$ & $\mathrm{CH}_{3}$ & $(-)$ ephedrine & 67 & $R$ & 18 (c) \\
\hline$\underline{1 b}$ & $\mathrm{C}_{2} \mathrm{H}_{5}$ & $\mathrm{CH}_{3}$ & (-) ephedrine & 68 & $R$ & $16(c)$ \\
\hline$\underline{1 c}$ & $\left(\mathrm{CH}_{3}\right)_{2} \mathrm{CH}$ & $\mathrm{CH}_{3}$ & (+) ephedrine & 63 & $\mathrm{~s}$ & 20 \\
\hline$\underline{1 \mathrm{~d}}$ & $\mathrm{C}_{6} \mathrm{H}_{5}-\mathrm{CH}_{2}$ & $\mathrm{CH}_{3}$ & $\begin{array}{l}(+) \text { ephedrine } \\
(-) \text { ephedrine }\end{array}$ & $\begin{array}{l}78 \\
71\end{array}$ & $\begin{array}{l}S \\
R\end{array}$ & $\begin{array}{l}31 \\
28\end{array}$ \\
\hline 1e & $\mathrm{C}_{6} \mathrm{H}_{11}-\mathrm{CH}_{2}$ & $\mathrm{CH}_{3}$ & (+) ephedrine & 73 & s & 17 \\
\hline$\underline{1 f}$ & $\mathrm{CH}_{3}$ & $\mathrm{C}_{2} \mathrm{H}_{5}$ & (-) ephedrine & 96 & $\mathrm{R}$ & 12 (c) \\
\hline$\underline{3 a}$ & $\mathrm{CH}_{3}$ & $\mathrm{H}$ & $(-)$ ephedrine & 80 & $\mathrm{R}$ & 10 (c) \\
\hline$\underline{3 b}$ & $\mathrm{H}$ & $\mathrm{CH}_{3}$ & (-) ephedrine & 60 & (e) & 0.5 \\
\hline$\underline{3 c}$ & (Cr & & (-) ephedrine & 72 & - & $0(d)$ \\
\hline
\end{tabular}

a) Unless stated, the ester or lactone $\left(10^{-2} \mathrm{M} \cdot \mathrm{L}^{-1}\right)$ were irradiated in $\mathrm{CH}_{2} \mathrm{Cl}_{2}$ at $-78^{\circ} \mathrm{C}$ with low pressure mercury lamps $(254 \mathrm{~nm})$ in the presence of ephedrine $\left(10^{-3} \mathrm{M} \cdot \mathrm{L}^{-1}\right)$.

b) The configuration of the major enantiomer was established by correlation with a known reference ; the enantiomeric excess was determined by NMR in the presence of $\mathrm{Eu}(\mathrm{hfc})_{3}$.

c) Ref. 14 and 17

d) The reaction was carried out at room temperature.

e) $|\alpha|_{D}=-0.64$. The configuration of the major enantiomer should be (R).

From kinetic measurements performed on the vinyl alcohol (18), we may anticipate that the reketonization step is the rate determining step and that the chiral discrimination occurs in two diastereomeric transition states such as $\underline{\underline{A}}$ and $\underline{\underline{B}}$ for $(-)$ ephedrine. In the absence of a very hindered group $R_{1}$, the major interaction represented in $\mathrm{A}$ will favour the other diastereoisomeric transition state $\underline{B}$ and therefore the $(R)$ configuration. 


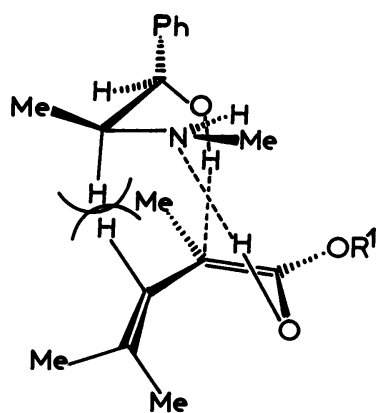

$\underline{\underline{A}}$

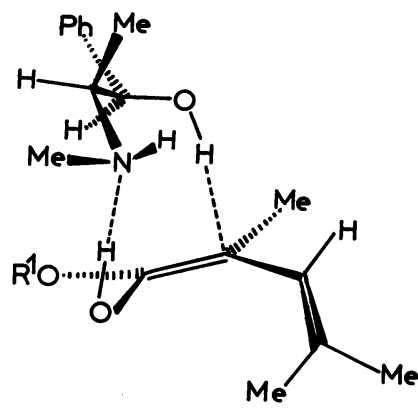

$\underline{\underline{B}}$

If such a mechanism is the only one involved at low temperatures a study of the influence of the temperature on the enantiomeric excess would enable us to determine the difference of activation parameters for the two diastereoisomeric transition states. A typical relation of $\log (x / 1-x)$ as a function of the inverse of the absolute temperature is given for 1e (figure 2). A linear relationship is obtained from $-10^{\circ} \mathrm{C}$ to $-45^{\circ} \mathrm{C}$ in $\mathrm{n}$-hexane and we deduce the following activation parameters for the chiral recognition : $\Delta \Delta \mathrm{H}^{\#}=-3.4 \mathrm{KJ} / \mathrm{Mol}$ and $\Delta \Delta \mathrm{S}^{\#}=-12.2 \mathrm{~J} / \mathrm{Mol}$. K. At higher temperatures the curvature observed might indicate that several processes can be involved in the reketonization step. At low temperatures the change of the shape of the curve might also be due to several reasons such as a change of viscosity, lower rates of reketonization ... (19).

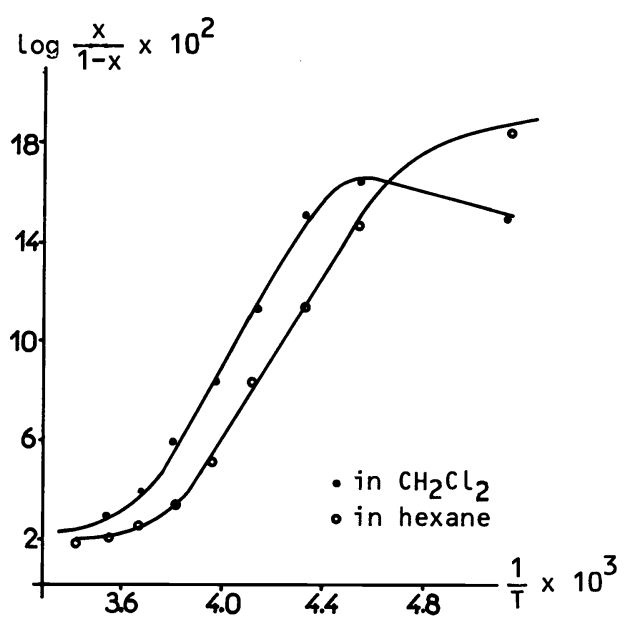

Figure 2 : Enantioselectivity as a function of the temperature for ester $1 \mathrm{e}$ at a concentration $10^{-2} \bar{M}$ in the presence of $(+)$ ephedrine $10^{-3} \mathrm{M} ; \mathrm{x}$ : concentration in the major enantiomer

For synthetic purposes very high selectivities have to be obtained to be of practical use. The introduction of a chiral alkoxy group in the starting ester might lead to good diastereoselectivities in the deconjugated ester. However, the low influence of the steric effect of the alkoxy group on the enantioselectivity of the deconjugation reaction indicates that very crowded chiral alkoxy groups would be needed to obtain important diastereoisomeric excess. The observed results confirm this hypothesis. Furthermore, as shown in the following equation, when the steric hindrance of the chiral alkoxy group becomes very important, the approach of the protic catalyst can only be made from one side of the dienol and the effect of the chirality of the catalyst is no more determining (20).

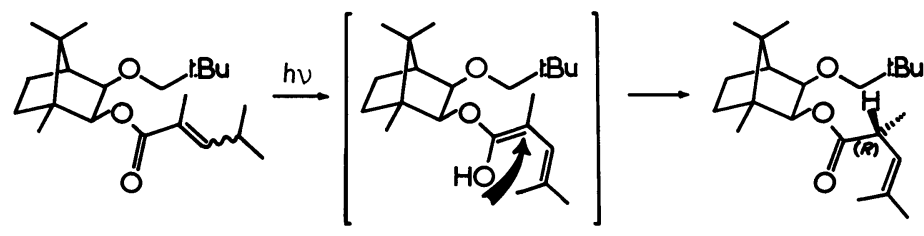

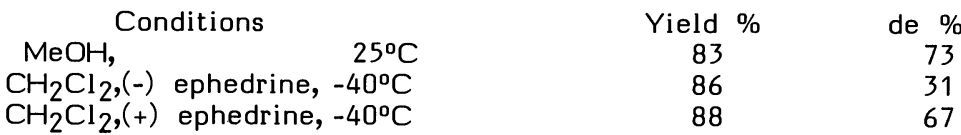


Finally, the enantioselective photodeconjugation of $\alpha, \beta$-unsaturated ketones is also possible as shown in the following example (21).
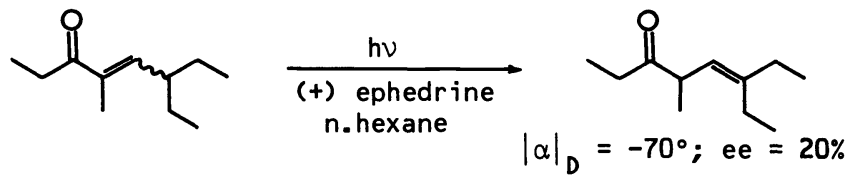

In all these reactions, it is remarkable that the $Z \Rightarrow E$ isomerization of the starting molecules and the photodeconjugation are the only observed transformations of the unsaturated carbonyl groups. The Michael type addition of the amino alcohol into the conjugated system and the radical addition of alkylamino radicals which might also be formed during the photolysis (22) were never detected in the reaction mixture. The only photochemical competitive reaction detected was a precipitation of minute amounts of ephedrinium hydrochloride when the photochemical experiments were carried out in methylene chloride at low temperature. However, the effects of this competing reaction on the enantioselectivity of the photodeconjugation process remain very low.

In conclusion, we have shown that it is possible to obtain important chiral discriminations in photochemical reactions, if strong interactions involving hydrogen bonding or charge transfer can be developed between a chiral catalyst and an intermediate having a lifetime long enough to allow the determining interactions to take place.

The model proposed to rationalize the observed selectivities involves cyclic diastereoisomeric transition states and a simultaneous action of the amino and hydroxyl groups of aminoalcohols in the reketonization step of conjugated dienols.

Acknowledgement We thank the Centre National de la Recherche Scientifique for financial help.

\section{REFERENCES}

1) H. Rau, Chem. Rev., 1983, 83, 535.

2) G. Balavoine, A. Moradpour and H.B. Kagan, J. Amer. Chem. Soc., 1974, 96, 5152.

3) a) G.L. Lange, C. Decicco, S.L. Tan and G. Chamberlain, Tetrahedron Lett., 1985, 4707

b) G.L. Lange and M. Lee, Tetrahedron Lett., 1985, 6163

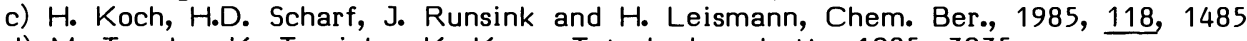

d) M. Tanaka, K. Tomioka, K. K.oga, Tetrahedron Lett., 1985, 3035

e) A. I. Meyers and S.A. Fleming, J. Amer. Chem. Soc., 1986, 108, 306

f) A. Nehrings, H.D. Sharf and J. Rinsink, Angew Chem. Int. Ed., 1985, 24, 877

g) ref. 1 and references cited therein.

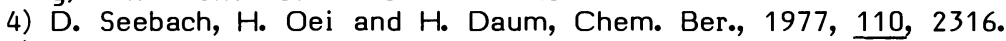

5) G.S. Hammond and R.S. Cole, J. Amer. Chem. Soc., 1965, 87, 3256.

6) W.H. Laarhoven and Th. J.M. Cuppen, J.C.S. Chem. Comm., 1977, 47.

7) a) M. Mousseron-Canet, M. Mousseron and P. Legendre, Bull. Soc. Chim., 1961, 1509

b) N.C. Yang, M.J. Jorgenson, Tetrahedron Lett., 1964, 1203

c) R. Ricard, P. Sauvage, C.S.K. Wan, A.C. Weedon and D.F. Wang, J. Org. Chem, 1986, 51, 62 + ref. therein.

8) a) R.R. Rando and W. von E. Doering, J. Org. Chem., 1967, 33, 1371

b) J.A. Barltrop and J. Wills, Tetrahedron Lett., 1968, 4987

c) I.A. Skinner and A.C. Weedon, Tetrahedron Lett., 1983, 4299.

9) a) K. Ohga and T. Matsuo, Bull. Chem. Soc. Japan, 1973, 46, 2181

b) F. Henin, R. Mortezaei and J.P. Pete, Synthesis, 1983, 1019.

10) R.M. Duhaime, D.A. Lombardo, I.A. Skinner and A.C. Weedon, J. Org. Chem., 1985, 50, 873.

11) a) A.C. Weedon, Can. J. Chem., 1984, 62, 1933

b) S.L. Eng, R. Ricard, C.S.K. Wan and A.C. Weedon, J.C.S. Chem. Comm., 1983, 236.

12) R.M. Duhaime and A.C. Weedon, J. Amer. Chem. Soc., 1985, 107, 6723.

13) T. Grasmtad, Acta. Chem. Scand., 1962, 16, 807.

14) R. Mortezaei, F. Henin, J. Muzart and J.P. Pete, Tetrahedron Lett., 1985, 6079.

15) O. Piva, F. Henin, J. Muzart and J.P. Pete, Tetrahedron Lett., 1986, accepted for publication.

16) R. Mortezaei, O. Piva, F. Henin, J. Muzart and J.P. Pete, Tetrahedron Lett., 1986, accepted for publication.

17) F. Henin, R. Mortezaei, J. Muzart and J.P. Pete, Tetrahedron Lett., 1985, 4945.

18) B. Capon and C. Zucco, J. Amer. Chem. Soc., 1982, 104, 7567.

19) R. Mortezaei and O. Piva, unpublished results.

20) R. Mortezaei, unpublished results.

21) J. Muzart, unpublished results.

22) R.C. Cookson, J. Hudec and N.A. Mirza, J.C.S. Chem. Comm., 1968, 180. 